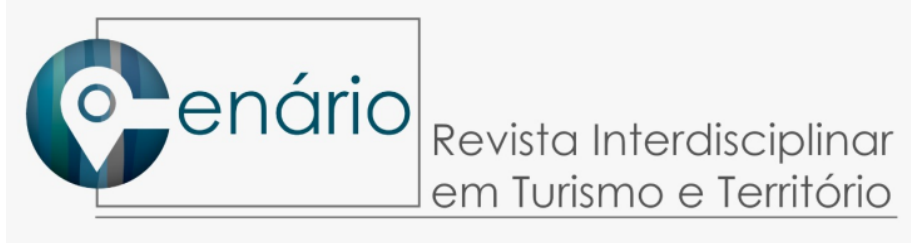

\title{
Políticas públicas frente aos impactos econômicos da COVID- 19 no Turismo
}

\author{
Políticas públicas frente a los impactos económicos de COVID-19 en el \\ turismo
}

\author{
Public policies in the face of the economic impacts of COVID-19 on \\ Tourism
}

\author{
Ana Cristina Fernandes Clemente ${ }^{1}$ \\ Lucas Goulart de Andrade ${ }^{2}$ \\ Edmur Antonio Stoppa ${ }^{3}$ \\ Glauber Eduardo de Oliveira Santos ${ }^{4}$
}

\begin{abstract}
Resumo: O objetivo desse artigo é apresentar as políticas públicas relacionadas a turismo e viagens que têm sido desenvolvidas no país, principalmente no estado de São Paulo, para reduzir o contágio e minimizar os impactos da pandemia da Covid-19. A metodologia utilizada é a combinação da pesquisa bibliográfica e documental, com a utilização da análise de conteúdo de documentos, tais como legislações, manuais e documentos publicados pelo governo federal, estadual e municipal em São Paulo, além daqueles produzidos por instituições econômicas e da área de turismo. Como resultado, pode-se identificar um impacto econômico representativo com a queda no fluxo de turistas, redução na movimentação de aeroportos e de rodoviárias, assim como cancelamento e adiamento de viagens, feiras e eventos. Dentre as políticas públicas desenvolvidas estão principalmente aquelas com orientações de como lidar com a pandemia, a implantação de quarentena, o isolamento social, os programas de subsídio à população e de crédito às pequenas e médias empresas, sendo o desafio pensar em políticas coordenadas e integradas com as diferentes esferas de governo, pensadas em curto, longo e médio prazo.
\end{abstract}

Palavras-chave: impacto econômico no turismo; pandemia covid-19; políticas públicas; São Paulo; coordenação intergovernamental.

Resumen: El propósito de este artículo es presentar políticas públicas relacionadas con el turismo y los viajes que se han desarrollado en Brasil, principalmente en el Estado de

\footnotetext{
${ }^{1}$ Doutoranda em Turismo pela Escola de Artes, Ciências e Humanidades (EACH), da Universidade de São Paulo (USP). Mestre em Turismo pela EACH USP. Especialista em Administração de Empresas pela Fundação Getúlio Vargas (FGV/SP). Atua na Secretaria de Turismo do Estado de São Paulo. E-mail: ana.clemente@sp.gov.br Orcid: https://orcid.org/0000-0003-1776-1407

2 Doutorando em Turismo pela Escola de Artes, Ciências e Humanidades (EACH), da Universidade de São Paulo (USP). Mestre em Turismo pela EACH USP. E-mail: lucasgoulart@usp.br Orcid: https://orcid.org/0000-0002-7346-5365

3 Doutor em Estudos do Lazer, Docente da Escola de Artes, Ciências e Humanidades (EACH), da Universidade de São Paulo (USP), nos cursos de Graduação em Lazer e Turismo e no Programa de PósGraduação em Turismo, nível Mestrado e Doutorado. É líder do Grupo Interdisciplinar em Estudos do Lazer (GIEL) e participante do ORICOLÉ (EEFFTO-UFMG). E-mail: stoppa@usp.br Orcid: https://orcid.org/00000002-7131-6454

4 Doutor em Economia do Turismo e do Meio Ambiente, doutor em Administração de Organizações da Universidade das ilhas Baleares, Palma de Mallorca, Espanha e da Universidade de São Paulo. E-mail: glauber.santos@usp.br. Orcid: https://orcid.org/0000-0001-8731-101X
} 


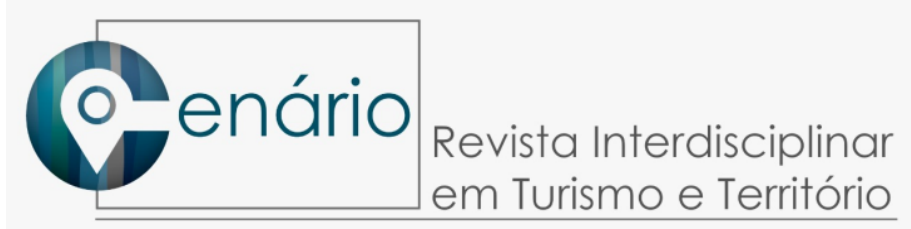

São Paulo, para reducir el contagio y minimizar los impactos de la pandemia de COVID19. La metodología utilizada es la combinación de investigación bibliográfica y documental, incluyendo legislación, manuales y documentos publicados por el gobierno nacional, del estado y del município de São Paulo, además de los producidos por instituciones económicas y de la área del turismo. Como resultado, se puede identificar un impacto económico significativo con la caída en el flujo de turistas, la reducción en el movimiento de aeropuertos y estaciones de autobuses, así como la cancelación y el aplazamiento de viajes, vacaciones y eventos. Entre las políticas públicas desarrolladas se encuentran principalmente aquellas de información sobre cómo enfrentar la pandemia, la implementación de programas de cuarentena, aislamiento social, subsidio de población y crédito a pequeñas y medianas empresas. El desafío de la gestión pública está siendo crear políticas coordinadas e integradas con las diferentes esferas de gobierno, pensadas a corto, largo y mediano plazo.

Palabras clave: impacto económico en el turismo; pandemia; COVID-19; políticas públicas; coordinación intergubernamental

Abstract: This article intends to present the tourism and travel public policies that have been implemented in Brazil, mainly in the State of São Paulo, to reduce contagion and minimize the impacts of the COVID-19 pandemic. The methodology is a combination of bibliographic and documental review, including legislation, manuals, and documents published by the federal, state, and municipal government of São Paulo, in addition to those produced by economic institutions and tourism organizations. Significant economic impact occurred due to the decrease in tourist flow, movement reduction in airports and bus stations, as well as cancellation and postponement of trips, exhibitions, and events. Some of the main public policies are those of information on how to deal with the pandemic, the implementation of quarantine, social distancing and isolation, as well as government subsidy programs to residents, and business credit programs to small and medium-sized companies. A challenge to public management has been to develop policies coordinated and integrated among different government bodies, oriented towards the short, medium, and long term.

Key-words: economic impact on tourism; COVID-19; pandemic; public policies; intergovernmental coordination.

\section{INTRODUÇÃO}

Na cidade Wuhan, capital da província de Hubei, na China, em dezembro de 2019, uma doença denominada Covid-19, provocada pelo novo coronavírus, teve seu foco inicial, alastrando-se de forma gradual por todo o mundo. Apesar de apresentar um baixo nível de fatalidade quando comparada a outras doenças globais recentes, como a SARS e a Gripe A (H1N1), a Covid-19 apresenta um grau de disseminação e contágio muito superior. Em decorrência disto, o quadro pandêmico da doença ocasionou uma grave crise no setor da saúde pública global, trazendo consequências grandiosas aos setores econômico e social em todo o mundo.

As atividades mais sensíveis às variações econômicas mundiais sofrem impactos ainda maiores e de difícil reversão. Esse é o caso do setor do turismo. Como uma atividade fundamentalmente não essencial ao consumidor, o turismo é caracterizado por uma demanda elástica (Santos \& Kadota, 2010), que apresenta alta tendência a regressão em tempos instáveis economicamente.

Companhias aéreas com redução de voos, hotéis fechados ou com baixa ocupação, atrativos turísticos sem visitantes, praias com proibição de acesso à faixa de 


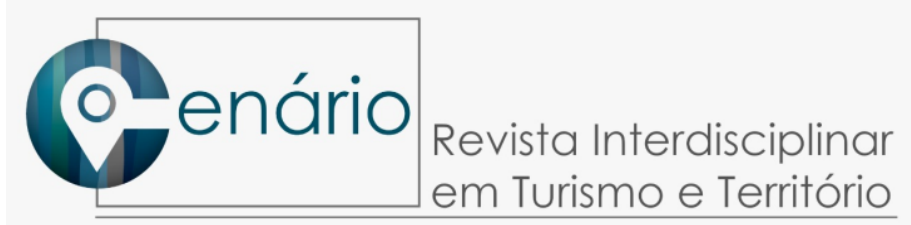

areia, agências de viagem que precisaram cancelar e adiar viagens e que estavam considerando demissões de funcionários, eventos e shows sendo remarcados ou suspensos são alguns dos impactos.

A partir disso, órgãos públicos e empresas, que dedicaram tantos recursos financeiros, tempo e equipe técnica para desenvolver grandiosas campanhas de promoção e marketing de destino, promovem agora uma ação inversa em prol da conscientização social por meio do slogan "adie sua viagem, fique em casa".

Os governantes implantaram medidas, por meio de leis, decretos, resoluções e portarias, como a implantação do estado de calamidade pública e da quarentena, as quais direcionam as pessoas a manter o isolamento social. Somente serviços essenciais estão em funcionamento, como saúde e segurança, além de mercados, farmácias, postos de combustível, agências bancárias, entre outros.

Segundo o relatório do Centro de Sistemas Científicos e Engenharia do Johns Hopkins (CSSE), até o dia 01 de maio de 2020 foram registrados 3.276 .373 casos de Covid-19 e um total de 233.988 mortes no mundo. Os países com maior número de casos são os Estados Unidos (1.070.032 casos); a Espanha (213.435 casos) e a Itália (205.463 mil casos). Esses países ultrapassaram a China, onde a epidemia se iniciou em dezembro de 2019, com cerca de 83 mil casos registrados (John Hopkins University, 2020).

No Brasil, segundo o Ministério da Saúde, foram registrados oficialmente 85.380 casos e 5.901 mortes até dia 01 de maio de $2020^{5}$. O maior número de casos está no estado de São Paulo, com 28.698 casos e 2.375 óbitos, sendo que mais $75 \%$ dos casos estão concentrados na capital paulista e região metropolitana de São Paulo (BRASIL, 2020; SÃO PAULO, 2020).

Diante desse cenário, o objetivo desse artigo é apresentar as políticas públicas relacionadas ao turismo $e$ as viagens que têm sido desenvolvidas no país, principalmente no estado de São Paulo, para reduzir o contágio e minimizar os impactos da pandemia da Covid-19 no setor.

A metodologia foi composta pela combinação da pesquisa bibliográfica e documental (SEVERINO, 2001), com esta última realizada em documentos de fontes secundárias listados abaixo, a partir da técnica de análise de conteúdo dos dados obtidos (TRIVIÑOS, 2013):

- Legislação federal, estadual e municipal com medidas de prevenção ao COVID-19.

- Publicações de órgãos e associações ligadas ao turismo, transporte, hotelaria, eventos e agenciamento de viagens, como ABAV, ANAC, OMT, Ministério do Turismo, FOHB, entre outras.

- Publicação de instituições econômicas, como Banco Mundial, Fundo Monetário Internacional e Fundação Getúlio Vargas;

- Boletins diários publicados pelo Centro de Inteligência e Estudos (CIET) da Secretaria de Turismo do Estado de São Paulo.

Considerando que a pandemia ainda está, infelizmente, em expansão e as políticas estão surgindo e sendo desenvolvidas rapidamente na maioria dos países do mundo, inclusive no Brasil, a coleta e análise dos dados compreende o período de 21 de março a 21 de abril de 2020.

\footnotetext{
${ }^{5}$ É importante destacar que esses números oficiais estão, segundo os especialistas da área e pelo Ministério da Saúde (G1, 2020), altamente defasados, pois muitos casos de infecção e de óbitos estão subnotificados, com o Brasil ocupando a última posição na quantidade de testagem de sua população.
} 


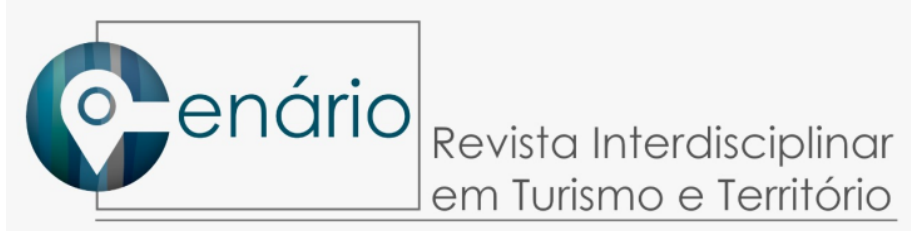

O artigo foi estruturado em três partes: inicialmente é apresentado o papel do turismo na economia e os impactos causados pela pandemia. Na sequência, são elencadas as políticas públicas de nível federal, estadual e municipal, com análise dos dados levantados sobre elas. Por fim estão as considerações finais e as referências.

\section{O PAPEL ECONÔMICO DO TURISMO NA ATUALIDADE E OS IMPACTOS DA COVID-19}

O turismo é uma das principais atividades de lazer da sociedade atual e apresenta papel relevante nos setores econômico e social. A atividade fomenta a geração de emprego e renda, promove o desenvolvimento econômico, possibilita aumento de divisas, permite valorização do patrimônio natural e monumental, além da permitir a quebra de fronteiras físicas e simbólicas que podem ajudar com a superação de preconceitos e desigualdades (Sathiendrakumar, 2013; Panosso Netto, 2010).

Entretanto, dentre os fatores negativos está sua considerável sensibilidade em meio a crises (Sathiendrakumar, 2013), como guerras, colapsos econômicos e pandemias. Os danos causados pela pandemia são notícia em todo o mundo em tempo real. As perdas econômicas têm sido crescente e as transformações nas esferas culturais e sociais impactaram as formas de convívio familiar, opções de lazer e novas formas de trabalho em casa.

Em 2019, o número de turistas no mundo atingiu cerca de 1,5 bilhão, de acordo com a Organização Mundial do Turismo - OMT (UWNTO, 2020). O impacto financeiro direto do setor no PIB mundial atual foi de aproximadamente USD 2,8 trilhões de dólares, e as expectativas sugeriam uma curva de crescimento ainda mais íngreme nos anos seguintes (WTTC, 2019).

Embora as crises econômicas afetem os mercados mundiais nos mais diversos setores, os que apresentam uma demanda caracteristicamente mais elástica estão mais sujeitos às flutuações econômicas. O turismo é um setor fortemente impactado quando há algum tipo de recessão econômica. O gráfico 1 apresenta uma média de crescimento em 10 anos no setor.

Gráfico 1: Crescimento do setor de turismo nos últimos 10 anos International Tourist Arrivals, World

(\% change)

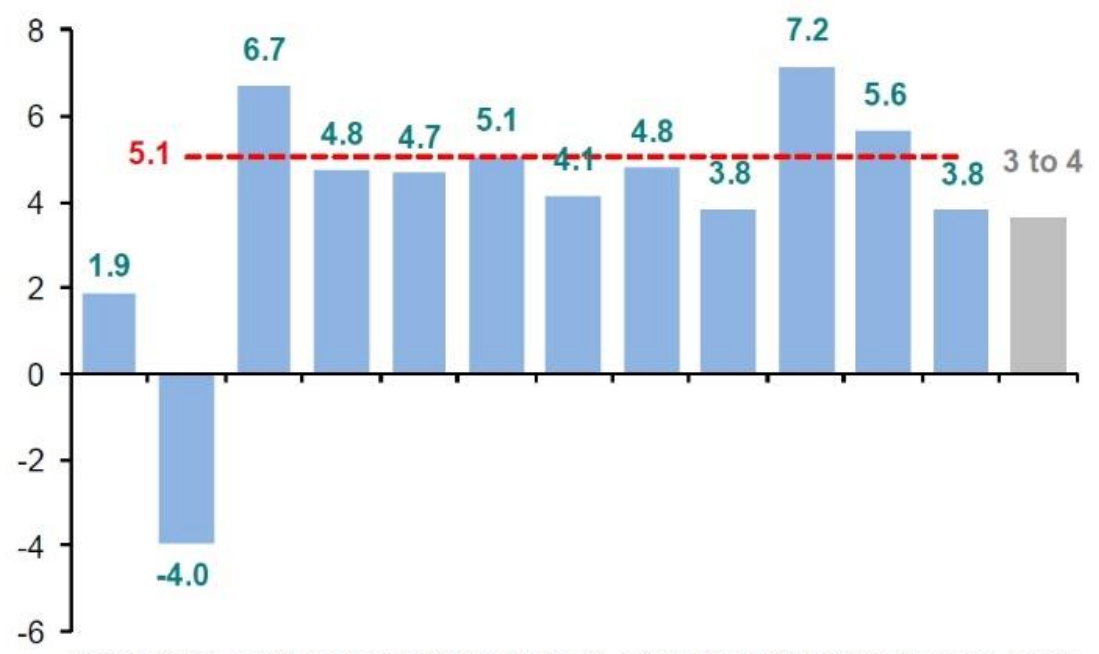

2008200920102011201220132014201520162017201820192020

-n-m 10-year average

Fonte: UNWTO, 2020

CENÁRIO|ISSN 2318-8561|Brasília|V.8, n. 14|73 - 85|Jun. 2020

DOI: 10.26512/revistacenario.v8i14.32210 


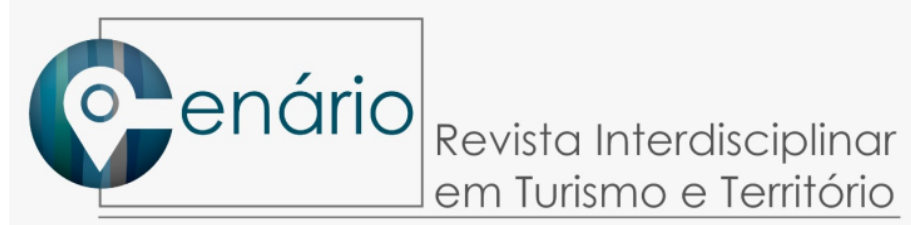

Apesar da sensibilidade do setor de turismo frente à crise financeira de 2008, que impactou fortemente o ano seguinte, é possível observar uma alta recuperação a partir de 2010, com um crescimento de $6,7 \%$ naquele ano. Tal fato pode sugerir uma boa capacidade de recuperação. No cálculo da média entre 2010 e 2019 obteve-se um crescimento médio de $5,1 \%$ do setor. O crescimento médio do PIB mundial no mesmo período foi de 2,9\% (World Bank, 2019; 2020), conforme gráfico 2.

Gráfico 2: Crescimento do PIB x Crescimento do Turismo

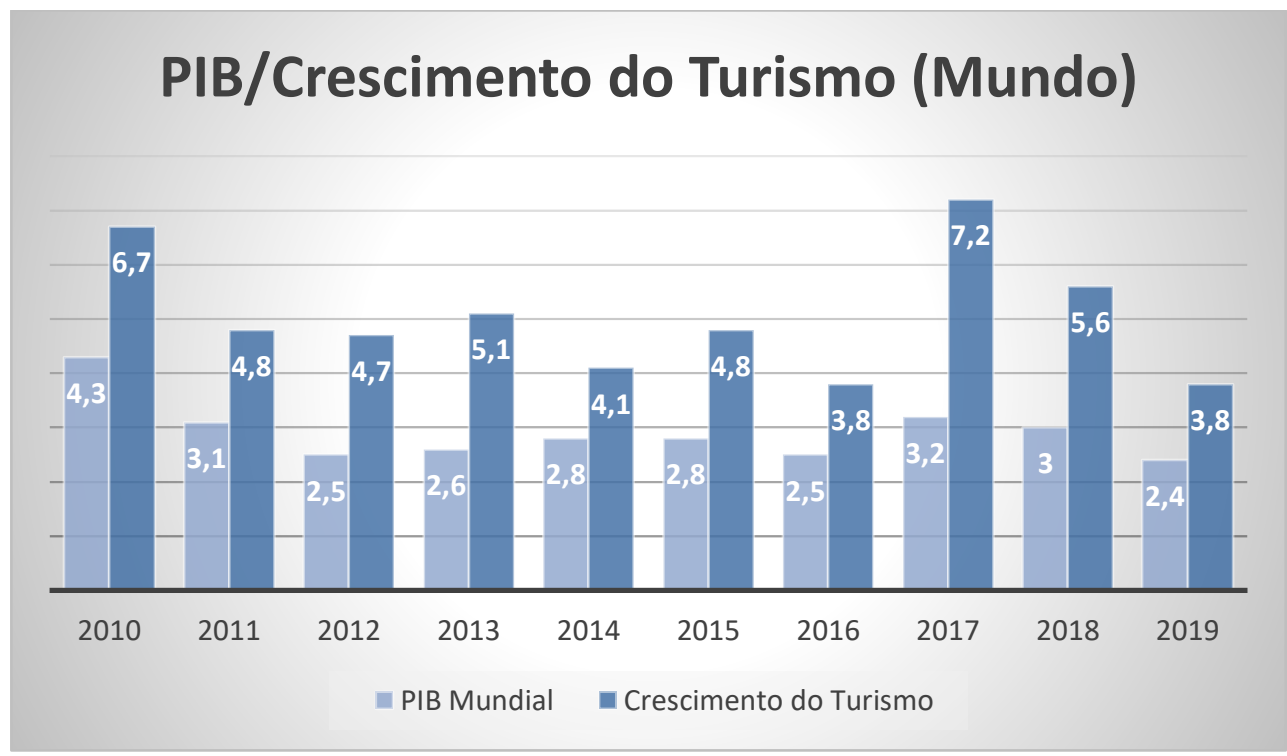

Fonte: Elaborado pelos autores com dados de World Bank (2019; 2020) e UNWTO (2020).

Com a disseminação da Covid-19, o Banco Mundial estima um crescimento de 2,5\% no PIB mundial e queda de $-5 \%$ no PIB nacional em 2020 (Work Bank, 2020; 2020b). Dentre os cenários desenhados pelo Fundo Monetário Internacional (FMI) os países mais desenvolvidos podem apresentar menor taxa de crescimento, enquanto que os países emergentes podem sofrer mais com desemprego e problemas sociais. Outro cenário aponta a possibilidade de retorno da pandemia no ano de 2021, havendo a necessidade de se pensar em estratégias a curto e longo prazo (IMF, 2020).

No setor de turismo a OMT estima uma queda de 20 a $30 \%$ de turistas internacionais em relação a 2019, o que representa uma perda de 300 a 450 bilhões de dólares na receita gerada, cerca de $35 \%$ do total gerado no ano anterior. Em comparação com a crise econômica de 2009, a queda de turistas internacionais foi de 4\% e com a pandemia do SARS em 2003 foi de 0,4\%. Com base em análise de tendências passadas, são 5 a 7 anos de crescimento perdido devido a pandemia (UNWTO, 2020b).

Segundo relatório da FGV sobre o impacto econômico da Covid-19 no turismo brasileiro, em 2019 o PIB do setor foi de $R \$ 270,8$ bilhões, em 2020 totaliza uma queda de 38,9\%, com perda de $\mathrm{R} \$ 116,7$ bilhões. Em 2021 o ganho econômico pode chegar a $\mathrm{R} \$ 259$,4 bilhões, o que não difere muito de 2019, mas para "compensar" as perdas será necessário um crescimento de em média 16\% nos anos seguintes de 2022 e 2023 (FGV, 2020). 


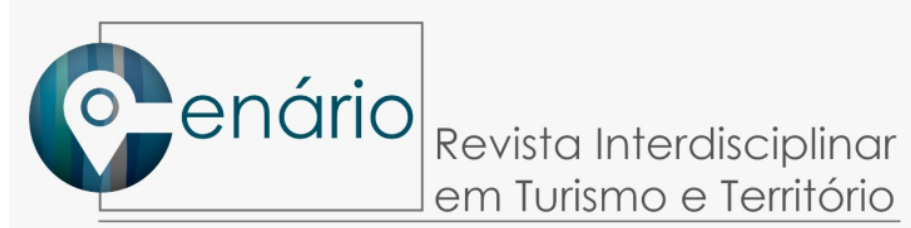

Antes da pandemia, o Brasil recebeu 6,6 milhões de turistas internacionais em 2018 (Brasil, 2019) com uma contribuição direta no PIB brasileiro de aproximadamente $\mathrm{R} \$ 190$ bilhões (WTTC, 2018). Apesar do ligeiro crescimento, a balança comercial do turismo no Brasil ainda é deficitária - em 2018, os estrangeiros gastaram US $\$ 6,3$ bilhões no país, enquanto os brasileiros gastaram US $\$ 22,2$ bilhões no exterior (UNWTO, 2020).

O turismo doméstico possui um impacto ainda mais significativo na economia nacional. Enquanto o turismo doméstico representa $73 \%$ do gasto de turismo no mundo, no Brasil os gastos nacionais em viagens totalizam $94 \%$ do setor - o gasto interno em viagens e turismo no ano de 2017 foi de aproximadamente US $\$ 100$ bilhões (WTTC, 2018b). Isso demonstra uma alta dependência do turismo nacional em relação ao mercado interno, conforme gráfico 3.

Gráfico 3: dependência do turismo interno nos países mais importantes, 2017

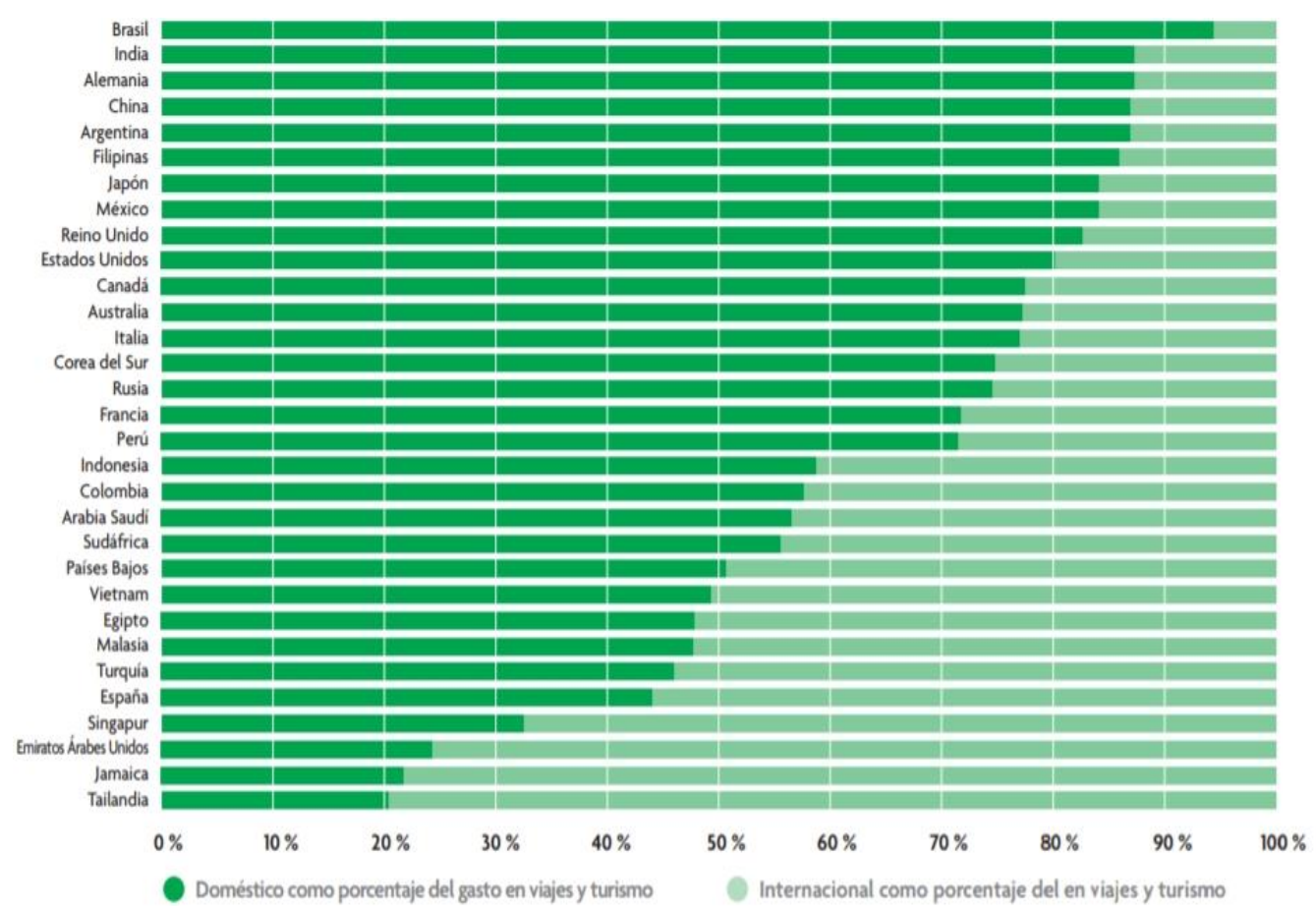

Fonte: WTTC, 2018b.

Dessa maneira, com a considerável dependência do país no turismo, qualquer alteração na dinâmica adotada afeta toda sua cadeia produtiva, desde funcionários de serviços de base em hotéis e resorts, agências de receptivo locais até a captação de investimentos de redes hoteleiras internacionais ou mesmo a atração de eventos e shows internacionais.

Em 2018, o mercado aéreo brasileiro registrou 815,9 mil voos domésticos que foram responsáveis pelo transporte de 93,6 milhões de pessoas (ANAC, 2018).

$A$ aviação foi um dos setores mais impactados com a crise. De acordo com a Agência Nacional de Aviação Civil - ANAC,

a malha emergencial é $91,61 \%$ menor do que a originalmente prevista pelas empresas para o período. Considerando a programação de Gol, Azul e Latam, a queda é de $56,06 \%$ das localidades atendidas, passando de 106 para 46. O número de voos semanais passou de 14.781 para 1.241 (ANAC, 2020). 


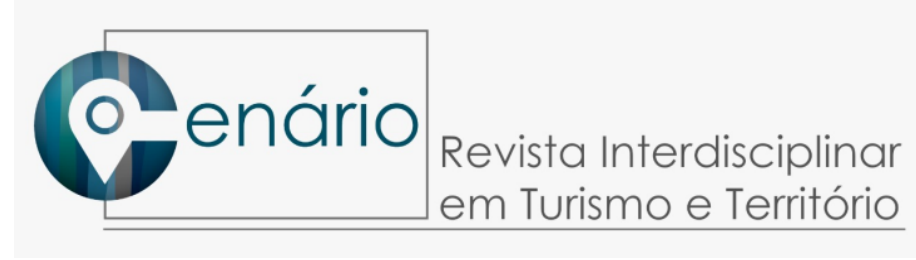

Em relação a hotelaria, em pesquisa do Fórum de Operadores Hoteleiros do Brasil - FOHB, no Brasil 69\% das acomodações estão fechadas. Sua maioria pretende retornar as atividades em junho (39\% da amostra). Na cidade de São Paulo fizeram parte da pesquisa 105 hotéis, que correspondem a 20.185 unidades habitacionais (UHs). Desse total, 63\% encontram-se fechados (FOHB, 2020).

As agências de viagem também sofreram grande impacto, de acordo com a ABAV Nacional (Associação Brasileira de Agências de Viagens), somente no mês de março a taxa de cancelamento de viagens foi de 85\% (ABAV, 2020).

A maior cidade do Brasil em número de turistas é São Paulo, com mais 15 milhões em 2017, sendo 2,7 milhões de estrangeiros, que geraram um gasto de $R \$ 12,4$ bilhões. O estado de São Paulo é o principal destino de negócios do país e sedia $75 \%$ das feiras e eventos, setor que foi fortemente impactado, com grande volume deles cancelados ou adiados (SPTURIS, 2018).

Assim, o contexto que sugeria a continuação do crescimento do setor nos próximos anos foi completamente transformado pelos impactos da Covid-19. As dimensões de tais impactos ainda são difíceis de serem mensuradas. O momento sugere, contudo, que políticas públicas efetivas sejam imediatamente aplicadas para reduzir a forte recessão que pode ser enfrentada pelo setor do turismo durante e após a pandemia. É de suma importância uma compreensão do cenário turístico nacional para atingir tal efetividade neste momento.

\section{POLITICAS PÚBLICAS DE TURISMO PARA PREVENÇÃO DO COVID-19}

De acordo com Fernandes (2007), as políticas públicas, reforçando seu caráter público, caracterizam-se como a junção multidisciplinar dos diferentes setores da sociedade, tais como educação, saúde, trabalho, segurança, esporte e lazer, tendo como principal foco o fomento de iniciativas que priorizem problemas da sociedade, desenvolvendo estratégias que ampliem as dimensões políticas, tendo como objetivos a tomada de decisões e negociações sociais.

Nesse contexto, a gestão dessas políticas, de acordo com Höfling (2001), consiste no Estado desenvolvendo um projeto de governo por meio de programas de ação direcionados a esses diferentes setores da sociedade, relacionados aos interesses e problemas sociais.

Considerando o momento de pandemia, um artigo e webinar de Oscar Motomura, CEO da Amana Key, uma das principais consultorias de gestão do país, destaca em relação aos governantes eleitos que

[...] há a premissa de que elegemos esses líderes para nos ajudar num mundo em certas condições. Ninguém no mundo foi eleito para nos conduzir no contexto de pandemia global. Nesse aspecto, estão todos zerados. Haverá os que estão pensando: "não fui eleito para isso..." Haverá outros que sentem que precisam assumir inclusive essa situação inédita de crise mundial ("fui eleito também para lidar com incertezas e desafios inéditos" [...]). (MOTOMURA, 2020, p.2).

Nesse sentido, as políticas públicas devem ser pensadas para cenários estáveis e de crise, de modo a garantir o bem estar dos sujeitos, de forma democrática e eficiente, a partir de decisões que avaliem seus impactos e benefícios econômicos e sociais. Abaixo são elencadas algumas políticas públicas ligadas às viagens e turismo definidas 


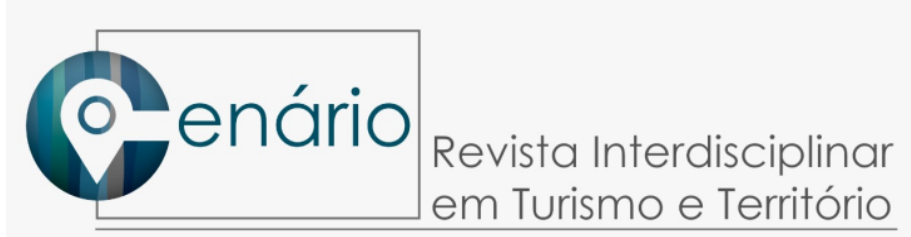

em nível federal, estadual e municipal para minimização dos impactos da pandemia do Covid-19.

Tabela 01: Ações do Ministério do Turismo para redução dos impactos no setor

\begin{tabular}{|c|c|c|}
\hline Ação & Descrição & A quem se destina \\
\hline $\begin{array}{l}\text { Fechamento de Fronteiras - } \\
\text { Portaria no } 08 \text { de } 02 \text { de abril } \\
\text { de } 2020 \text {, Portaria } \\
\text { Interministerial no } 132 \text {, de } 22 \\
\text { de março de } 2020 \text { e Lei } \\
13.979 \text {, de } 06 \text { de fevereiro } \\
\text { de } 2020 \text {, sobre enfretamento } \\
\text { da Pandemia }\end{array}$ & $\begin{array}{l}\text { Dispõe sobre a restrição excepcional e } \\
\text { temporária de entrada no País de } \\
\text { estrangeiros provenientes da Argentina, } \\
\text { Bolívia, Colômbia, Guiana Francesa, } \\
\text { Paraguai, Peru, Suriname e Uruguai. }\end{array}$ & $\begin{array}{l}\text { Estrangeiros de } \\
\text { países de fronteira }\end{array}$ \\
\hline Repatriação & $\begin{array}{l}\text { Atua no auxílio ao regresso de } \\
\text { brasileiros no exterior. Foram mais de } \\
15 \text { mil brasileiros que fizeram pedido de } \\
\text { repatriação. }\end{array}$ & $\begin{array}{l}\text { Brasileiros fora do } \\
\text { país }\end{array}$ \\
\hline $\begin{array}{l}\text { Campanha "Não cancele, } \\
\text { remarque" }\end{array}$ & $\begin{array}{l}\text { Para evitar um colapso financeiro ainda } \\
\text { maior no setor pelo risco de abundantes } \\
\text { pedidos de reembolso, a campanha visa } \\
\text { conscientizar o consumidor, quando } \\
\text { possível, não cancelar sua viagem }\end{array}$ & $\begin{array}{l}\text { Consumidores de } \\
\text { viagens }\end{array}$ \\
\hline $\begin{array}{l}\text { Manutenção de Empregos - } \\
\text { Medida Provisória } 936\end{array}$ & $\begin{array}{l}\text { A fim de manter aproximadamente } 8,5 \\
\text { milhões de empregos, sendo } 1 \text { milhão } \\
\text { no setor de turismo, o Governo Federal } \\
\text { destinou verba de } R \$ 51 \text { bilhões para } \\
\text { permitir que empresas executem a } \\
\text { flexibilização de salário e jornadas de } \\
\text { trabalhos por } 03 \text { meses }\end{array}$ & Empresas do setor \\
\hline $\begin{array}{l}\text { Regras de } \\
\text { cancelamento/remarcações } \\
\text { para serviços turísticos e } \\
\text { culturais }\end{array}$ & $\begin{array}{l}\text { Isenta o prestador de serviços ou } \\
\text { sociedade empresarial de reembolso } \\
\text { imediato ao consumidor. Concede um } \\
\text { prazo de até } 12 \text { meses, após decretado } \\
\text { o fim da pandemia. }\end{array}$ & Empresas do setor \\
\hline $\begin{array}{l}\text { Nota Técnica Conjunta - } \\
\text { Plataforma } \\
\text { Consumidor.gov.br }\end{array}$ & $\begin{array}{l}\text { Plataforma criada para evitar a } \\
\text { judicialização de demandas, } \\
\text { proporcionando contato direto entre } \\
\text { consumidores e empresas. Objetiva } \\
\text { auxiliar a redução dos efeitos da } \\
\text { pandemia no setor. }\end{array}$ & $\begin{array}{l}\text { Consumidores de } \\
\text { viagens e empresas } \\
\text { do setor }\end{array}$ \\
\hline
\end{tabular}

\section{Linhas de Crédito}

(Fungetur - Redução de Juros e Aumento de Prazo)
Medidas de facilitação de acesso ao crédito, por meio de liberação de fundos ao setor. Obtém-se de tal medida: a redução dos juros de 5\% para 7\% ao ano; a ampliação da carência de 6 meses para 1 ano; a possibilidade da aplicação de $100 \%$ dos recursos no capital de giro.

Banco do Brasil, BNDES e Inclusão das empresas do segmento Caixa Econômica Federal turístico nas linhas de crédito disponíveis pelo Banco do Brasil, BNDES e Caixa Econômica Federal.

Medida Provisória Recursos da Embratur
Liberação de recursos da Embratur para recuperação do setor, aplicadas em recursos como: execução de medidas de apoio ao setor turístico em âmbito
Empresas do setor

Empresas do setor

Consumidores de viagens e empresas do setor 


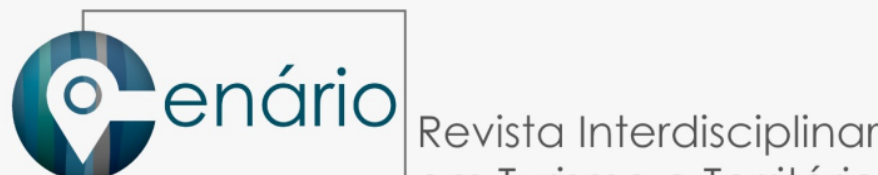 \\ em Turismo e Território}

nacional; campanhas publicitárias; incentivo ao reestabelecimento de viagens; e auxílio no processo de repatriação de brasileiros.

MP 948, de 08 de abril de Dispõe sobre o cancelamento de 2020 setores de turismo e cultura serviços, de reservas e de eventos dos
Consumidores de viagens e empresas do setor

Fonte: elaborado pelos autores com dados do Brasil, 2020b e 2020c.

Tabela 02: Ações Governo do Estado de São Paulo para redução dos impactos no setor

\begin{tabular}{|c|c|c|}
\hline Ação & Descrição & $\begin{array}{l}\text { A quem se } \\
\text { destina }\end{array}$ \\
\hline $\begin{array}{l}\text { Decreto } n^{0} 64.864, \\
\text { de } 16 \text { de março de } \\
2020\end{array}$ & $\begin{array}{l}\text { Dentre as medidas, suspende a realização de eventos } \\
\text { com aglomeração de pessoas em qualquer número }\end{array}$ & População \\
\hline $\begin{array}{l}\text { Decreto } n^{\circ} 64.865 \\
\text { de } 18 \text { de março de } \\
2020\end{array}$ & $\begin{array}{l}\text { Dentre as medidas, suspende o funcionamento de } \\
\text { shopping centers, galerias e estabelecimentos } \\
\text { congêneres }\end{array}$ & População \\
\hline $\begin{array}{l}\text { Decreto } n^{0} 64.879 \\
\text { de } 20 \text { de março }\end{array}$ & $\begin{array}{l}\text { Dentre as medidas, reconhece estado de calamidade } \\
\text { pública e suspende as atividades de natureza não } \\
\text { essencial (parques estaduais, etc.) }\end{array}$ & População \\
\hline $\begin{array}{l}\text { Decreto } n^{0} 64.881 \\
\text { de } 22 \text { de março }\end{array}$ & $\begin{array}{l}\text { Decreta a medida de quarentena, complementa a } \\
\text { proibição de consumo local em bares, restaurantes e } \\
\text { padarias. Em termos de turismo, inclui hotéis como } \\
\text { serviços essenciais de saúde. }\end{array}$ & População \\
\hline $\begin{array}{l}\text { Programa de } \\
\text { Crédito Turístico - } \\
\text { SP }\end{array}$ & $\begin{array}{l}\text { Voltado a fornecimento de créditos para empresas } \\
\text { ligadas ao turismo. Até o momento foram } 1.554 \\
\text { empresas cadastradas e pedido de } R \$ 471,6 \text { milhões. } \\
\text { A ação é feita em conjunto com a Desenvolve SP, } \\
\text { BNDES e Caixa Econômica Federal. }\end{array}$ & $\begin{array}{l}\text { Empresas } \\
\text { do setor }\end{array}$ \\
\hline $\begin{array}{l}\text { Campanhas de } \\
\text { conscientização }\end{array}$ & Campanhas para adiamento de viagens & $\begin{array}{l}\text { Empresas, } \\
\text { população, } \\
\text { etc. }\end{array}$ \\
\hline $\begin{array}{l}\text { Monitoramento dos } \\
\text { impactos no turismo }\end{array}$ & $\begin{array}{l}\text { Implantação de um centro de pesquisa com boletins } \\
\text { diários dos impactos do Covid-19 no turismo paulista }\end{array}$ & $\begin{array}{l}\text { Empresas, } \\
\text { população, } \\
\text { etc. }\end{array}$ \\
\hline
\end{tabular}

Fonte: São Paulo, 2020c; São Paulo, 2020d; CIET, 2020.

Em se tratando de políticas municipais, as prefeituras do Estado de São Paulo publicaram decretos com medidas a serem seguidas. Em pesquisa do CIET com 158 cidades turísticas, no qual analisou cerca de 250 decretos, foram elencadas algumas medidas: 


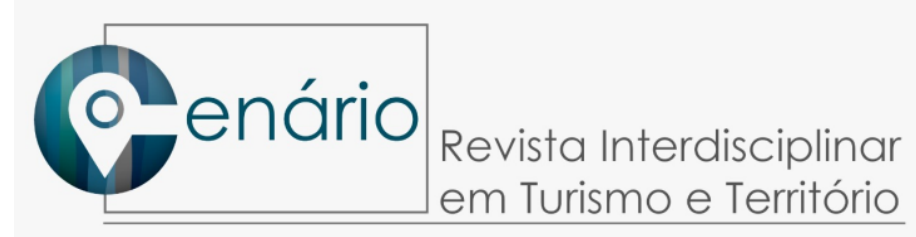

Gráfico 7: Medidas municipais de turismo

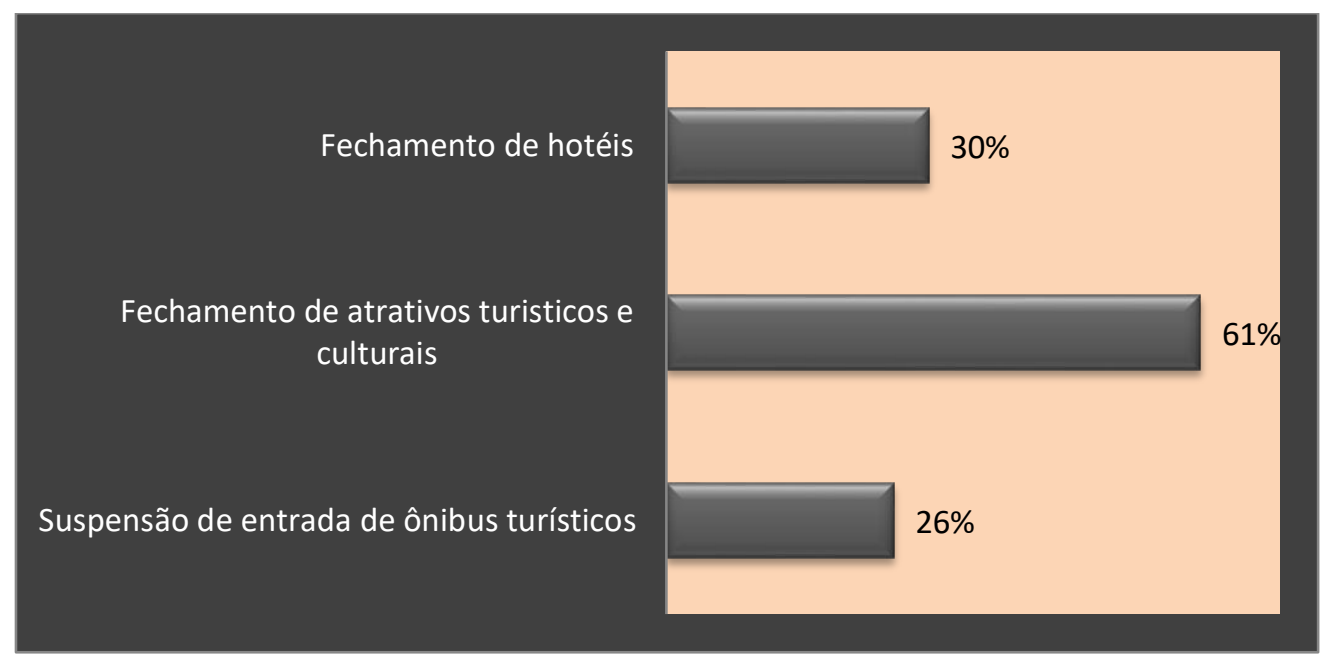

Fonte: elaborado pelos autores com dados do CIET, 2020.

Em relação aos hotéis, esse percentual se refere aqueles fechados para fins turísticos. Outros fins como estadia de profissionais da saúde e repatriados são atendidos. Em relação à suspensão de entrada de ônibus se aplica principalmente a cidades do litoral ou que tem uma grande demanda em feriados e finais de semana. Dentre outras medidas identificadas estão também barreiras sanitárias ou bloqueios nas rodovias (CIET, 2020).

A partir dos dados apresentados, pode-se considerar que ainda não há uma política clara de fortalecimento do setor para o longo prazo, nem de retomada do turismo. Não há ou há pouca integração e articulação entre as políticas públicas desenvolvidas em nível federal, estadual e municipal, com direcionamentos diferentes que acabam por dificultar a quarentena e o controle da doença.

Para Abrucio (2005) a coordenação intergovernamental é uma das saídas para garantir o equilíbrio na cooperação e competição entre os entes federados, visando otimizar uso de recursos, auxiliar governos menos capacitados e mais pobres, incentivando associativismo e formas de gestão mais efetivas.

\section{CONSIDERAÇÕES FINAIS}

O turismo é uma atividade de vital importância para a sociedade, não somente por fortalecer os negócios e a balança comercial dos países, mas também por ser uma das principais atividades de lazer da sociedade atual, favorecendo a promoção e valorização cultural e ambiental. É a tendência moderna de fuga dos problemas rotineiros, mas também de construção de novos valores sociais e políticos.

O turismo apresentou rápida recuperação após a crise de 2008. O fato de o turismo doméstico representar $94 \%$ do setor no país pode ser benéfico para sua recuperação, visto que o setor interno pode apresentar maior fôlego para a retomada econômica após a crise. Mas, para isso, sua retomada deve ser bem planejada, o que deve envolver a ação integrada dos órgãos públicos, da iniciativa privada e da sociedade civil.

Sendo assim, faz-se relevando desenvolver políticas públicas coordenadas e articuladas pelos diversos níveis de governo. A união de forças e a participação de todos 


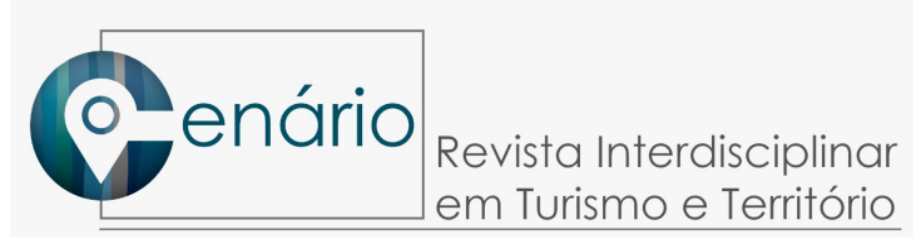

na definição das ações é um dos caminhos mais promissores, que deve ser seguido de forma democrática e eficiente, com planos de curto e longo prazo.

\section{REFERÊNCIAS}

ABAV Nacional. Associação Brasileira de Agências de Viagens. (2020). Ações conduzidas pela ABAV Nacional para o enfrentamento da crise da COVID-19. Disponível em <https://drive.google.com/file/d/1c4s4GJnwNWFIVPJnmMInuN0xFggCvUWu/view>. Acesso em 13 abril. 2020.

ABRUCIO, F. L. A coordenação federativa no Brasil: a experiência do período $\mathrm{FHC}$ e os desafios do governo Lula. Rev. Sociol. Polit., Curitiba, n. 24, p. 41-67, June 2005 - Disponível em <http://www.scielo.br/scielo.php?script=sci_arttext\&pid=S0104$44782005000100005 \& \mathrm{lng}=\mathrm{en} \& \mathrm{nrm}=\mathrm{iso}>$. Acesso em 19 fev. 2019.

ANAC. Agência Nacional de Aviação Civil. (2018). Anuário do Transporte Aéreo. Sumário Executivo. Brasília/DF.

ANAC. Agência Nacional de Aviação Civil. (2020). Malha aérea essencial começa no sábado (28). Disponível em <https://www.anac.gov.br/noticias/2020/malha-aereaessencial-comeca-no-sabado-28>. Acesso em 13 abr. 2020.

Brasil, Ministério do Turismo. (2019). Anuário Estatístico de Turismo. Ano base 2018. Volume 46 - 1ª Edição. Brasília, Distrito Federal.

Brasil, Ministério da Saúde. (2020). Covid-19: Painel Coronavirus no Brasil. Disponível em <https://covid.saude.gov.br/> Acesso em 20 abri. 2020.

Brasil, Ministério do Turismo. (2020b). Manual sobre o Coronavírus. Disponível em < http://www.turismo.gov.br/images/Cartilha_Coronavirus.pdf>. Acesso em 20 abr.

Brasil. Medida Provisória MP no 948, de 08 de abril de 2020 (2020c). Diário Oficial da União, Publicado em: 08/04/2020, Edição: 68-A, Seção: 1 - Extra, p. 1. Órgão: Atos do Poder Executivo. Disponível em < http://www.in.gov.br/en/web/dou/-/medida-provisorian-948-de-8-de-abril-de-2020-251768019>. Acesso em 12 abri. 2020.

Brida, J. G., \& Risso, W. A. (2009). Tourism as a factor of long-run economic growth: An empirical analysis for Chile. European Journal of Tourism Research, 2(2).

CIET - Centro de Inteligência e Estudos de Turismo, Secretaria de Turismo do Estado de São Paulo. (2020). Boletins Diários - Monitoramento Impactos Covid-19 no Turismo Paulista. Disponível

em $<$ https://www.turismo.sp.gov.br/publico/noticia_tour.php?cod_menu=123>. Acesso em 21 abr. 2020.

Fernandes, A. S. A.. (2007) Políticas Públicas: definição evolução e o caso brasileiro na política social. In: DANTAS, H. e MARTINS JUNIOR, J. P. (Orgs). Introdução à política brasileira. São Paulo: Paulus. 


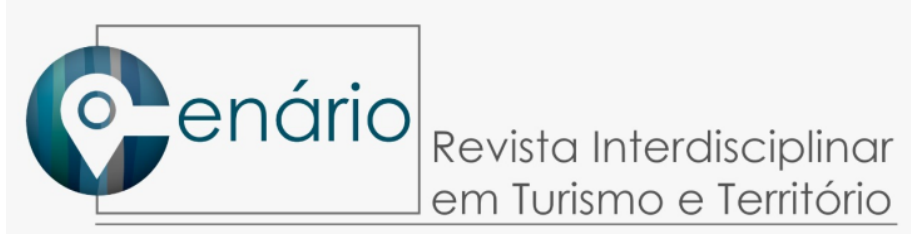

FOHB - Fórum dos Operadores Hoteleiros do Brasil. (2020). Oferta de Disponibilidade Hoteleira. Disponível em < https://www.panrotas.com.br/hotelaria/mercado/2020/04/fohb-69-dos-hoteis-de-redeno-brasil-se-encontram-fechados_172894.html>. Acesso em 20 abri. 2020.

G1. Globo, com. Bem Estar - Subnotificação: 4 indicadores de que há mais casos de Covid-19 no Brasil do que o governo divulga. 2020. Disponível em $<$ https://g1.globo.com/bemestar/coronavirus/noticia/2020/04/29/subnotificacao-4indicadores-de-que-ha-mais-casos-de-covid-19-no-brasil-do-que-o-governodivulga.ghtml>. Acesso em 29/04/2020.

Höfling, E. de M. (2001). Estado e políticas públicas sociais. Cadernos CEDES. Campinas, vol. 21, n‥ 55.

John Hopkins University (JHU CCA). COVID-19 Dashboard. (2020). Disponível em < https://www.arcgis.com/apps/opsdashboard/index.html\#/bda7594740fd40299423467b4 8e9ecf6>. Acesso em 13 abr. 2020.

Motomura, O. (2020). Reflexões OM (2) sobre como estamos vivendo hoje. Disponível em: https://amana-key.com.br/webinar-aberto-amana-key-mar-20/. Acesso em 30 mar. 2020.

Panosso Netto, A. (2010). O que é Turismo. São Paulo: Brasiliense.

Panrotas. O impacto da COVID-19 em viajantes e empresas de turismo (2020). Panrotas Edição no 1.417 - Ano 28 , 8 a 14 de abril de 2020. Disponível em < https://issuu.com/panrotas/docs/panrotas1417-03 $04 \quad 20201729$ 41>. Acesso em 13 abri. 2020.

Santos, G. E. de O; Kadota, D. K. (2012). Economia do Turismo. São Paulo: Aleph.

Sathiendrakumar, R. Sustainable Tourism Development: its feasibility and economic vale. (2013) IN Clemente, A. T. Handbook of Tourism Economics: Analysis, New Applications and Case Studies. Singapure: World Scientific Publishing Co. Pte. Ltd.

São Paulo, Secretaria de Estado de Saúde. (2020). Novo Coronavirus (COVID-19):

Situação em Epidemiológica (2020). Disponível em <http://www.saude.sp.gov.br/cvecentro-de-vigilancia-epidemiologica-prof.-alexandre-vranjac/areas-de-

vigilancia/doencas-de-transmissao-respiratoria/coronavirus-covid-19/situacaoepidemiologica>. Acesso em 15 abr. 2020.

São Paulo, Governo do Estado. (2020c) Decretos estaduais. Disponíveis em < https://www.saopaulo.sp.gov.br/spnoticias/decretos-do-governo-de-sp-com-medidasde-prevencao-e-combate-ao-novo-coronavirus/> Acesso em 20 abr. 2020.

São Paulo, Secretaria de Turismo. (2020d). Programa de Crédito Turístico. Disponível em < https://www.turismo.sp.gov.br/publico/noticia.php?codigo=1766>. Acesso em 21 abr. 2020.

SPTURIS. São Paulo Turismo. (2018). São Paulo: Cidade do Mundo. Dados e fatos dos eventos, viagens e turismo na capital paulista. Edição 2018. São Paulo. 


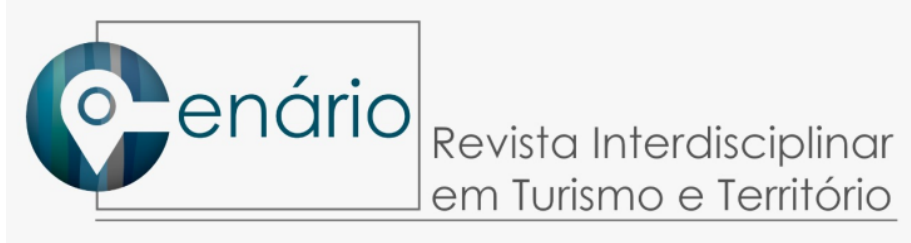

Sequeira, T. N., \& Maçãs Nunes, P. (2008). Does tourism influence economic growth? A dynamic panel data approach. Applied Economics, 40(18), 2431-2441.

Severino, J. A. Metodologia de Trabalho Científico. (2010). 23. cd. rev. catual. 5. reimp. São Paulo: Cortez.

Triviños, A. N. S. (2013) Introdução à pesquisa em ciências sociais: a pesquisa qualitativa em educação. $1^{\mathfrak{a}}$ ed. 22. reimpr. São Paulo. Atlas.

Tugcu, C. T. (2014). Tourism and economic growth nexus revisited: A panel causality analysis for the case of the Mediterranean Region. Tourism Management, 42, 207212.

United Nations World Tourism Organization (UNWTO). (2020). World Tourism Barometer. Volume 18. Issue 1.

United Nations World Tourism Organization (UNWTO). (2020). Compendium of tourism Statistics. Data 2014-2018. 2020 Edition. Madrid, Spain.

United Nations World Tourism Organization (UNWTO). (2020b). Tourism and Covid-19. Disponível em < https://www.unwto.org/tourism-covid-19>. Acesso em 13 abr. 2020.

United Nations World Tourism Organization (UNWTO). (2020c). Supporting Jobs and Economies Through Travel \& Tourism: a call for action to mitigate the sócio-economic impacto f convid-19 and accelerate recovery.

World Bank. World Bank Group. (2019). The World Bank - Data. GDP Growth.

World Bank. World Bank Group. (2020). Global Economic Prospects: slow growth, policy challenges. Washington/DC.

WTTC. World Travel \& Tourism Concil. (2018). Travel \& Tourism economic impact 2018 Brazil.

WTTC. World Travel \& Tourism Concil. (2018b). Domestic Tourism: Importance \& Economic Impact.

WTTC. World Travel \& Tourism Concil. (2019). Travel \& Tourism Economic Impact 2019 World. 